\title{
Fiber optics based schemes modeling and simulation of QoS for Wi-Fi scenarios using OPNET modeler
}

\author{
Suhad Hasan Rhaif ${ }^{1}$, Adnan Hussein Ali ${ }^{2}$, Rana K. Abdulnabi ${ }^{3}$, Ali Abdulwahhab Abdulrazzaq ${ }^{4}$ \\ ${ }^{1,4}$ Middle Technical University, Technical Instructors Training Institute, Baghdad, Iraq \\ ${ }^{2,3}$ Middle Technical University, Institute of Technology, Baghdad, Iraq
}

\begin{tabular}{l} 
Article Info \\
\hline Article history: \\
Received May 4, 2019 \\
Revised Nov 24, 2019 \\
Accepted Dec 6, 2019 \\
\hline
\end{tabular}

\section{Keywords:}

End to end delay

OPNET

Wi-Fi

Wireless LAN

\begin{abstract}
Wireless Fidelity (Wi-Fi) network is created on the IEEE 802.11 standard. Connections for local devices in homes and business arenas are provided by Wi-Fi units. With the growing demand as well as penetration of wireless services, the wireless networks users now assume Quality of Service (QoS) besides performances comparable to what is accessible from secure networks. In this paper, OPNET Modeler is used as module and for the simulation of a fiber optic-based Wi-Fi network within a fixed local area network. The aim of this paper is to evaluate their Quality of service (QoS) performances in terms of Wi-Fi voice-packet delay and End-to-End for both Wi-Fi base fiber and Wi-Fi base line. Many scenarios, with same Physical and MAC parameters, have many subnet networks are implementing with fiber optics baseline in addition to $\mathrm{Wi}-\mathrm{Fi}$ baseline, were created in the network OPNET simulation tool for obtaining the results. The results of simulation reveal that base line demonstrated more delay than base fiber.
\end{abstract}

Copyright $\odot 2020$ Institute of Advanced Engineering and Science. All rights reserved.

Corresponding Author:

Adnan Hussein Ali,

Department of Technical Electronics,

Middle Technical University,

Muasker Al Rashid Street, 7F7P+JG Baghdad, Baghdad, Al Zafranyia, Iraq.

Email: dr.Adnan@mtu.edu.iq, aaddnnaann63@gmail.com

\section{INTRODUCTION}

The Wireless Local Area Network (WLAN) found in the principles of IEEE 802.11, was introduced in early 1990s. The purpose introducing it was to have a best-effort package access network with no wires. A WLAN product can be bought by any user because it uses an unlicensed band. This implies that any user can make use of WLAN without any permission. As a result of this, WLAN has experienced rapid growth and acceptance in the consumer market, and it is also embedded within several portable devices. Towards the late 1990s, the WLAN became the most preferred choice of communication amongst individual users [1]. This drove many companies towards creating one standard for high speed WLAN by forming Wireless Fidelity (Wi-Fi) Alliance, which would be globally accepted [2]. The IEEE 802.11, is the bedrock of this standard.

High-speed Internet access is provided by Wi-Fi through cables within wireless hotspots that have greatly increased productivity and convenience for users. In the world today, Wi-Fi high-speed WLAN connectivity is used by millions of offices, restaurants, homes, airports and several other public places. The high demand for $\mathrm{Wi}-\mathrm{Fi}$ is as a result of the flexibility and mobility which it offers at a cost that is affordable. It has been reported that from 2004 to 2012 the usage popularity of Wi-Fi around the world has increased by over 4 times [3]. In addition, to its flexibility and mobility, wireless technology can be easily accessed in areas that are expensive and difficult to reach using conventional wired infrastructure.

The basic model of the 802.11 protocol was submitted in 1997 [4]. After that time, several other protocols have been introduced. The aim of designing the standard IEEE 802.11 through specific revisions be situated for solving the problems associated with the wireless local area coverage. Thus, the IEE 802.11 was 
designed to address the problems of high data cost, various modulations with frequency transmission, enhanced Quality of Service (QoS) as well as improved security and authentication mechanisms [5]. All these problems were channeled to the Wireless Fidelity Alliance.

In order to authenticate the interoperability of the adopted $802.11 \mathrm{~b}$ products, which is an improved version of the previous 802.11, a test suite was implemented by the Wi-Fi Alliance; the operating band of the former $802.11 \mathrm{~b}$ is ISM and it offers data rates up for more than $12 \mathrm{Mbps}$ in both ad-hoc and infrastructure modes for client-to-client (C2C) connections [6]. Subsequent to the introduction and certification of the IEEE $802.11 \mathrm{~g}$ as an extended version of the IEEE $802.11 \mathrm{~b}$, it has continued to function within the same frequency range. However, its data rate is up to 54Mbps [7], and it is compatible with $802.11 \mathrm{~b}$ devices. Through the use of a larger group of modulation options, higher data rates are achieved. The IEEE 802.11i protocol was another significant modification [8], which provides a novel and stronger authentication and security schemes. This protocol was specifically designed to address the security problems which accompanied Wi-Fi. In order to make Wi-Fi products a metro-access deployment options, external modifications through software and hardware were made to the standard [9]. The two main modifications that were made to the standard with the aim of addressing two different usage models are as follows:

- Fixed-access or usage of last-mile-IEEE 802.11 together with high gain antennas

- Portable-access or usage of hot-zone-IEEE 802.11 mesh networks

The following radio frequencies are used by the Wi-Fi products which are accompanying with the option of metro-access deployment:

- The 802.11a standard utilizes $5 \mathrm{GHz}$ in the AP-to-AP interlink.

- The standards of $802.11 \mathrm{~b}$ and $802.11 \mathrm{~g}$ using a $2.4 \mathrm{GHz}$.

The most commonly used frequency bands for wireless networks, especially Wi-Fi equipment are the 2.4 and $5 \mathrm{GHz}$, which are categorized as shared common use [10]. This means that many users or operators can make use of these frequencies simultaneously in accordance with the principles established by regulation so as to minimize the probability of interference between emissions. A novel extension of 802 standards called 802.11e was introduced in 2005 by IEEE with the aim of standardizing QoS enhancement efforts. The purpose of doing this was to solve the problem of QoS provisioning caused by the use of MAC techniques such as Distributed Coordinated Function (DCF) Point Coordination Function (PCF) in the previous versions [11]. QoS support for Wi-Fi has been greatly enhanced by the techniques of MAC in IEEE 802.11e.

The aim of this research is to determine the behavior to which the fiber optics-based schemes quality of service (QoS) replaces the conventional baseline while employing the Baseline Scenario of IEEE WLAN Standard. In order to achieve this aim, we carefully designed, developed and simulated several network scenarios using the OPNET modeler. The results of the various baselines QoS parameters, thus obtained through the simulation, were then analyzed, and published in the literature.

\section{TECHNOLOGIES AND METHODS}

\subsection{WiFi modifications}

The Institute of Electrical and Electronics Engineers (IEEE) established a set of rules for wireless local area networks (WLANs) with a longtime sponsor Intel to the all IEEE 802.11 standards. The majority of recent works on IEEE 802.11 have given more attention to increasing the speed of transmission and range, adding novel features and enhancing the Quality of Service (QoS). However, in more recent times, the latest IEEE 802.11 version which is IEEE $802.11 \mathrm{n}$, is in high demand, thereby causing a shift in the focus to faster solutions, especially the versions of IEEE 802.11ac and IEEE 802.11ad. These modifications are geared towards the provision of WLAN gigabit speed. A modification between the two versions lies in their frequencies. The throughput of IEEE 802.11ac is delivered over the $5 \mathrm{GHz}$ band, thus resulting in easy movement from IEEE $802 \mathrm{n}$, which also makes use of $5 \mathrm{GHz}$ band and 2.4 band. On the other hand, IEEE 802.11ad makes usage of the unlicensed band at $60 \mathrm{GHz}$ and its transmission range is shorter, as in Table 1 . The following can be achieved by means of improving the range and speed of wireless transmissions [12]:

- The high definition TV (HDTV) performances as well as digital video streams can be improved in homes and in progressive use in enterprise networks.

- Enhance the reduction of capital expenditures by businesses through the elimination of laying cost and cost of Ethernet cabling maintenance.

- Increasing the range and hot spots performances.

- Agreeing connections for handling more clients

- Improving complete user practice where and each time users are connected 
Table 1. Wireless LAN throughput by IEEE standard

\begin{tabular}{|c|c|c|}
\hline IEEE WLAN Standard & Over-the-Air (OTA) Estimates & $\begin{array}{l}\text { Media Access Control Layer, Service Access } \\
\text { Point (MAC SAP) Estimates }\end{array}$ \\
\hline IEEE $802.11 \mathrm{~b}$ & $11 \mathrm{Mbps}$ & $5 \mathrm{Mbps}$ \\
\hline IEEE $802.11 \mathrm{~g}$ & $54 \mathrm{Mbps}$ & $25 \mathrm{Mbps}$ (when. $11 \mathrm{~b}$ is not present) \\
\hline IEEE $802.11 \mathrm{n}$ & Up to $600 \mathrm{Mbps}$ & Up to $400 \mathrm{Mbps}$ \\
\hline IEEE & Up to $867 \mathrm{Mbps}$ with 2 antennas and $80 \mathrm{MHz}$; & Up to $600 \mathrm{Mbps}$ with 2 antennas and $80 \mathrm{MHz}$; \\
\hline $802.11 \mathrm{ac}$ & Up to $1.3 \mathrm{Gbps}$ with 3 antennas and $80 \mathrm{MHz}$ & Up to $900 \mathrm{Mbps}$ with 3 antennas and $80 \mathrm{MHz}$ \\
\hline $\begin{array}{l}\text { IEEE } \\
802.11 \mathrm{ad}\end{array}$ & $\begin{array}{l}\text { At least } 1.1 \text { Gbps (up to } 4.6 \mathrm{Gbps} \text { in some first- } \\
\text { generation products) }\end{array}$ & $\begin{array}{l}\text { Up to } 700 \mathrm{Mbps} \text { for } 1.1 \mathrm{Gbps} \text { OTA } \\
\text { (up to } 3 \mathrm{Gbps} \text { for } 4.6 \mathrm{Gbps} \text { OTA) }\end{array}$ \\
\hline
\end{tabular}

Wi-Fi is based on standard of IEEE third modulation. The frequency band in which the Wi-Fi operates on is the $2.4 \mathrm{GHz}$, and it is capable of providing data transfer reaching $54 \mathrm{Mbps}$ with a maximum rate [12]. The orthogonal frequency division modulation scheme may be utilized at data rates of $6,12,18,24$, 36, 48, and $54 \mathrm{Mbps}$. It comes back to complementary code keying (CCK) at a rate of $5.5 \mathrm{Mbps}$ besides 11 Mbps, in addition to direct-sequence spread spectrum (DSSS) for 1 and 2 Mbps [13]. The integration of $\mathrm{Wi}-\mathrm{Fi}$ into electronic devices, laptops and smartphones has made Wi-Fi access easier. Wi-Fi is made up of two components, which are firstly, an access point while the second is wireless client station, as presented in Figure 1. The second station can be regarded as any operator device like a computer which possesses as a card of wireless network, while the access point is described as the linkage between wireless and fixed networks. The functions of the access point include connecting to the Digital Subscriber Line (DSL) or a cable modem, organizing and granting access from different wireless stations to the fixed network and providing wired and wireless Ethernet clients with Internet services [14].

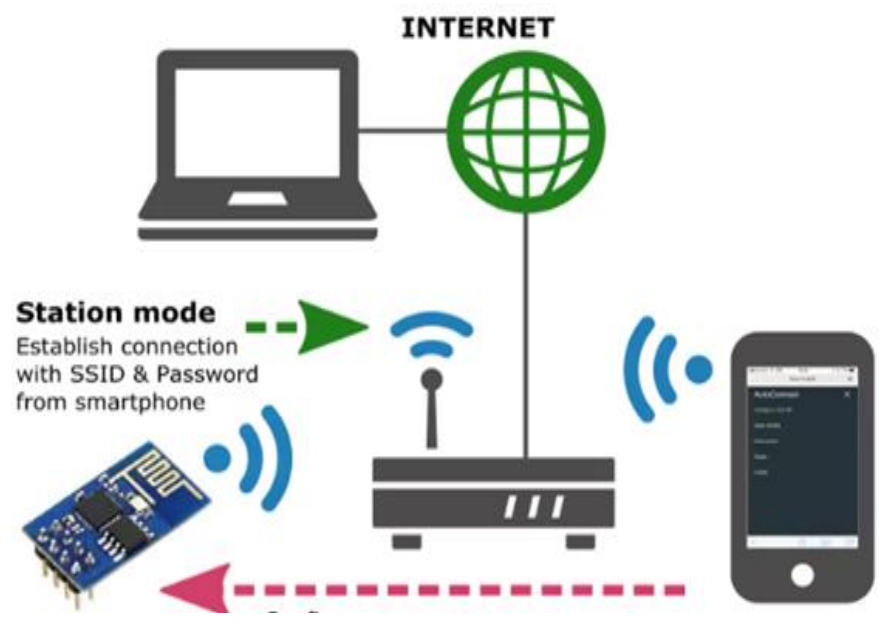

Figure 1. Wi-Fi client/station connection

\subsection{Wi-Fi security mechanisms}

Security remains one of the major challenges of wireless networking. There are three basic reasons why security mechanisms for wireless transmission are implemented: (i) Authentication; for the verification of the identity of the approved stations of communicating client; (ii) confidentiality; for ensuring that the information which is transferred through a wireless network keeps on private and more protect; (iii) integrity; for ensuring that the several MAC-level protocol data units (MPDU) that have been transmitted will get to their destination intact, without any changes made to them [15]. Authentication occurs at the Link Level amongst Wi-Fi stations, while integrity and confidentiality functions are performed within the MAC security sublayer, which is a level higher than the PHY layer [16].

While WLANs operate over the shared medium, malicious technologies can be used by unauthorized users to eavesdrop and gain access to sensitive and important information. There were so many security flaws in the initial standard (Wired Equivalent Piracy) WEP, which led to the implementation of another encryption system Wi-Fi Protection Access (WPA) and subsequently WPA2 by the Wi-Fi forum. Despite the fact that WPA and WPA2 provide more security and better protection, they are still found wanting as they are not secure enough. Therefore, the implementation of encryption algorithms that are more complex without decreasing the throughput of the MAC layer becomes crucial $[17,18]$. 


\subsection{Technological limitations of the 802.11 family}

Irrespective of the frequency bands in which all standards operate, there are some limitations which the 802.11 subfamily possesses and must be considered before making a decision on the scope, coverage or speed that can be achieved.

These five limitations are discussed as follows:

- Scope (range): despite the fact that commercial speech is up to $100 \mathrm{~m}$, there are two factors that determine this data: firstly, the presence and location of obstacles on the route between the access point and the terminal, and secondly intrusion and weather conditions. Thus, a range with good weather and outdoor antenna terminals can be good considerations.

- Bandwidth: the various standards can be adhered to in air channel. However, the speed of using air channel is slow because of the effect which the required protocols have on the transmission of user information through air channel [19, 20]. More so, environmental conditions affect the quality of communication between the access point and a terminal by adjusting the communication width. That is the reason why sometimes the Access Point connection could be $11 \mathrm{Mbps}, 5 \mathrm{Mbps}, 2 \mathrm{Mbps}$ or even in 1 Mbps.

- Quality of service (QoS): Not all traffic is equally relevant from the users' perspective. For instance, a VoIP call should be of greater priority than file transfer. Wi-Fi protocols are more common and do not have any mechanism for prioritizing a certain kind of traffic over another. This is can be harmful, especially when there is a mixture of traffic flows and different requirements such as voice and data [21, 22].

- Security: No sophisticated security is possessed by Wi-Fi because the aim of introducing it was just to transmit data over the air. So just little attention has been given to Wi-Fi security [23]. However, the successful implementation of this technology led to publications on its security limitation. Hence, it became crucial to improve the technology in terms of security. Furthermore, the majority of the initial weakness of Wi-Fi technology is solved by the 802.11i, which makes it safe in fixed networks

- Mobility: it is widely assumed that wireless networks are mobile and therefore not connected to a fixed location [24]. It is not possible to make use of a Wi-Fi network from a vehicle that is moving at a normal speed due to reasons associated with physical speed, which affects the coverage range of the access point. This implies that a user will have to connect to another access point when the other access point is out of range. This is another limitation of the standard, which makes users to be disconnected from an access point.

\section{WIFI SIMULATION SETUP}

OPNET Modeler, 14.5 have been used to simulate Wi-Fi scenarios [25]. Wi-Fi scenarios are used the parameters shown in Table 2. Three OPNET models were created for both fixed and Wi-Fi local area networks so as to assess their performance. OPNET solutions test devices of communications, technologies, protocols, architectures, and a simulation of their environmental performances in a dynamic virtual network. During the course of the work, a connection of three subnets is implemented. In reign one subnet, a BC that has a server for video and audio streaming is connected to the Internet Cloud. In reign two, there is a subnet that receives audio and video data and then distributes the content of the data from a Base Station to different subscriber stations (SS) subnets around it. All the SS subnets are Wi-Fi enabled and have the capability of receiving the distributed data over Wi-Fi link to multiple computers.

Table 2. Wi-Fi parameters

\begin{tabular}{ll}
\hline \multicolumn{1}{c}{ Items } & \multicolumn{1}{c}{ Wi-Fi 802.11 n\&g } \\
\hline Scenario & Indoor dense deployment \\
Frequency & $5.745 \mathrm{GHz} @$ Unlicensed Spectrum \\
& $2.630 \mathrm{GHz} @$ licensed Spectrum \\
Bandwidth & $20 \mathrm{MHz}$ \\
Base station & $251 \mathrm{DT} \mathrm{Wi-Fi} \mathrm{AP}$ \\
Tx power & $0.1 \mathrm{~W}$ \\
Data Rate & $11 \mathrm{Mbps}$ \\
Receiver Power Threshold & $-95 \mathrm{dBm}$ \\
Buffer Size & 1024000 bits \\
Access Point Functionality & Enabled \\
Traffic Type & DL Traffic only, UDP full buffer \\
\hline
\end{tabular}

Int J Elec \& Comp Eng, Vol. 10, No. 3, June 2020 : 2569 - 2578 


\subsection{Baseline Wi-Fi scenario}

The use of different WLAN scenarios alongside OPNET standard models was employed so as to establish the Baseline Scenario of 802.11g model. In order to obtain the configuration of an actual network in the framework of an implemented WLAN, a single WLAN infra-structure 802.11g was studied. The Internet Protocol IP cloud which considered as a backbone Internet, is done with a T1 Point-to-Point (1.544Mbps) serial link. The three subnets are positioned on the three sides of such IP cloud through an IP gateway linked by Point-to-Point Protocol PPP T1 link and two servers connected over a central switch using 100 BaseT, as shown in Figure 2.

The network traffic server is connected by 100BaseT Ethernet on the one side of the Internet Protocol (IP) cloud, the server connected to the firewall with Ethernet wiring 100BaseT and can be utilized by means of source and destination to all services: video conferencing, voice applications in the WLAN 802.11g throughout the simulation. Figure 3 presents the baseline Wi-Fi application configuration; the heavy and light video as well as PCM voice was used in the scenario, also, the profile of the baseline $\mathrm{Wi}-\mathrm{Fi}$ configuration is contained, where the applications for transmission of data in the scenario are evaluated.

The subnet one is a representation of the remote branch office, which is made up of an office-LAN with workstations that are connected by a 100BaseT link. The office LAN is connected throughout a controlling switch by means of 100 Base T Ethernet wiring that mimics a real-world office environment, which with a fasting Ethernet LAN standard. A connection of LAN and an IP cloud can be established by an IP gateway. The use of 100BaseT Ethernet wiring is employed by the gateway to connect to the office LAN, while a serial link of Point-to-Point T1 (1.544Mbps) is used in establishing a gateway and the IP cloud connection, as shown in Figure 4.

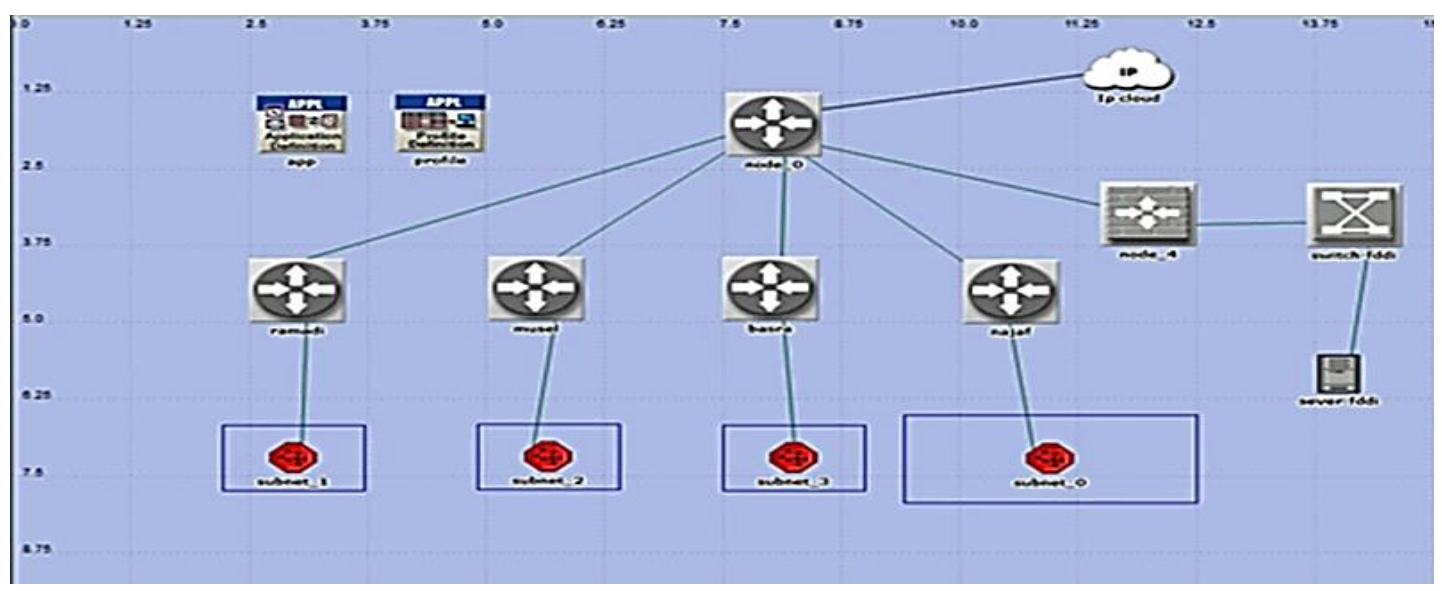

Figure 2. Simulated wire server with four subnets
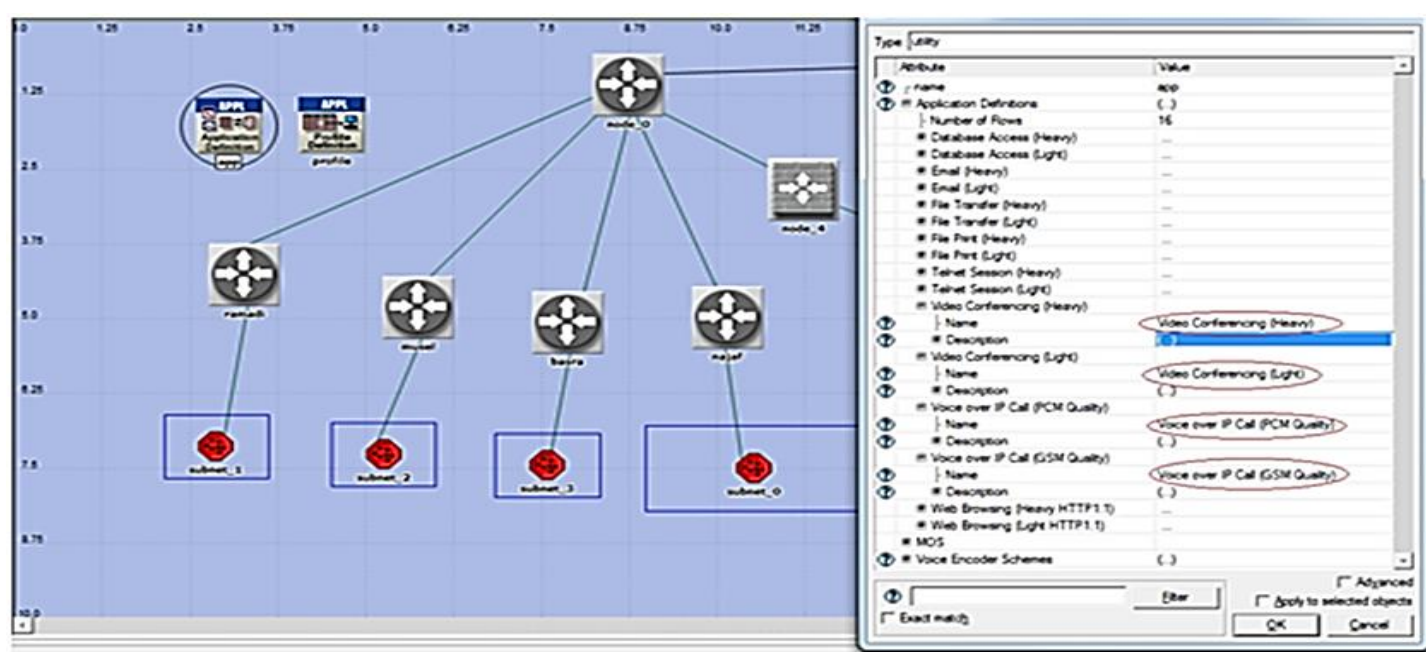

Figure 3. The Wi-Fi baseline application configuration 


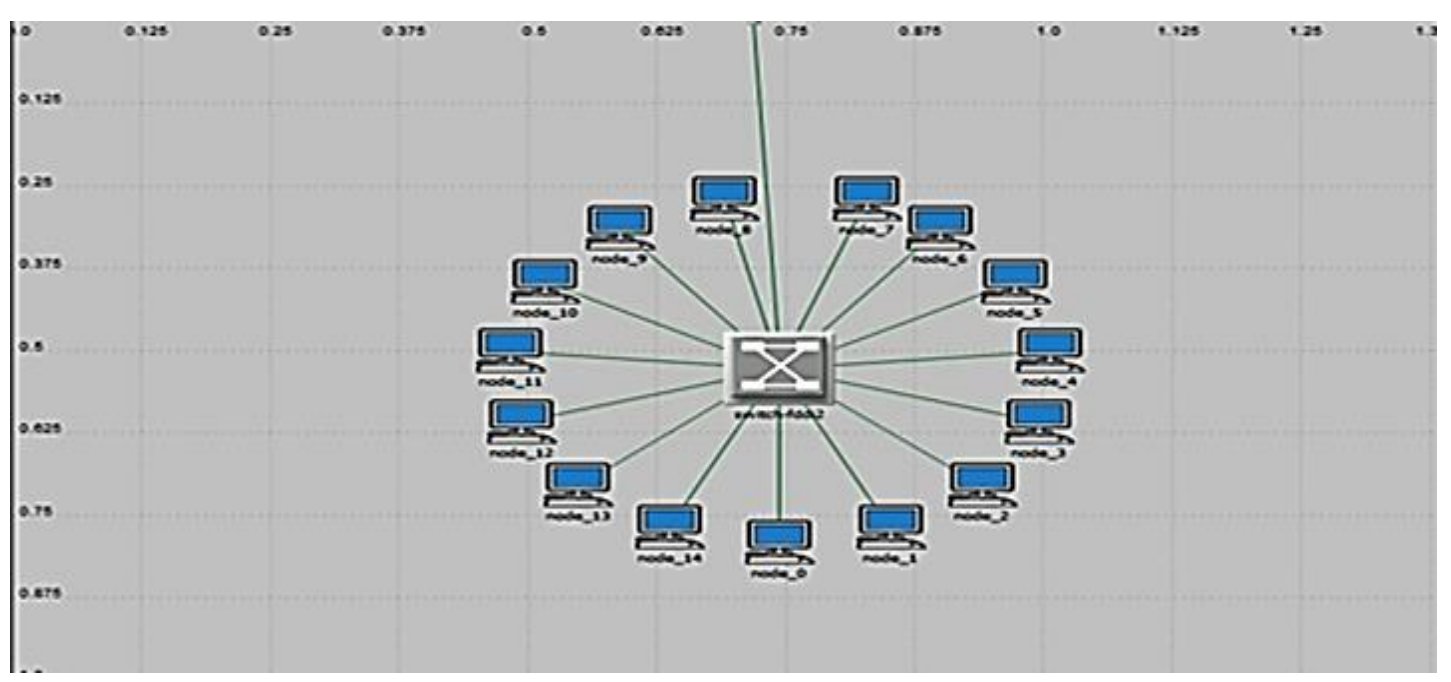

Figure 4. Subnet (1) 802.11g LAN

The subnet two is positioned on the both sides of the Internet Protocol cloud, and a connection is established between the LAN and an office LAN via its access point through a central point, which makes use of Ethernet wiring with a standard Fast Ethernet LAN. The fast Ethernet LAN has a WLAN which extends to an area where cabling is difficult or an area that requires aesthetics such as media or conference rooms. The LAN is connected to an Internet Protocol IP cloud by an Internet Protocol gateway, which uses 100BaseT Ethernet wiring, while a serial link of 1.544Mbps Point-to-Point T1 is used in establishing the IP gateway with an IP cloud connection, as shown in Figure 5.

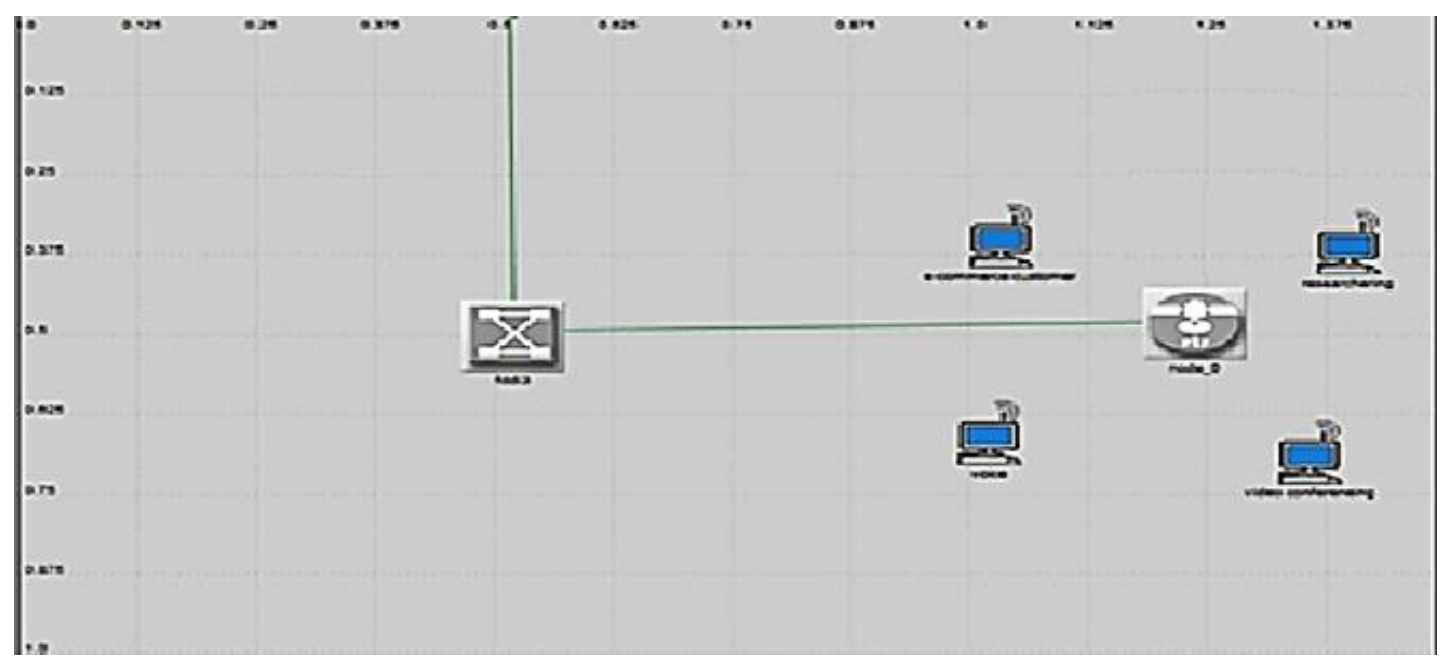

Figure 5. Subnet $2802.11 \mathrm{~g}$ WLAN

\subsection{Fiber optic Wi-Fi scenario}

In this scenario, all Ethernet components were replaced using Fddi, while Fddi link was used in replacing all the 100 baseT.

- Fddi gateway used to replace Ethernet gateway

- Fddi2 firewall used to replace Ethernet firewall

- Fddi16 used in replacing Ethernet_switch16

- 100baseT link replaced by Fddi link

- Fddi server used to replace the Ethernet server

Figures 6-8 show the outcomes of the fiber networks. Finally, Subnet three represents the combination of both subnet (1) and subnet (2) with the same parameter configurations as shown in Figure 9. 


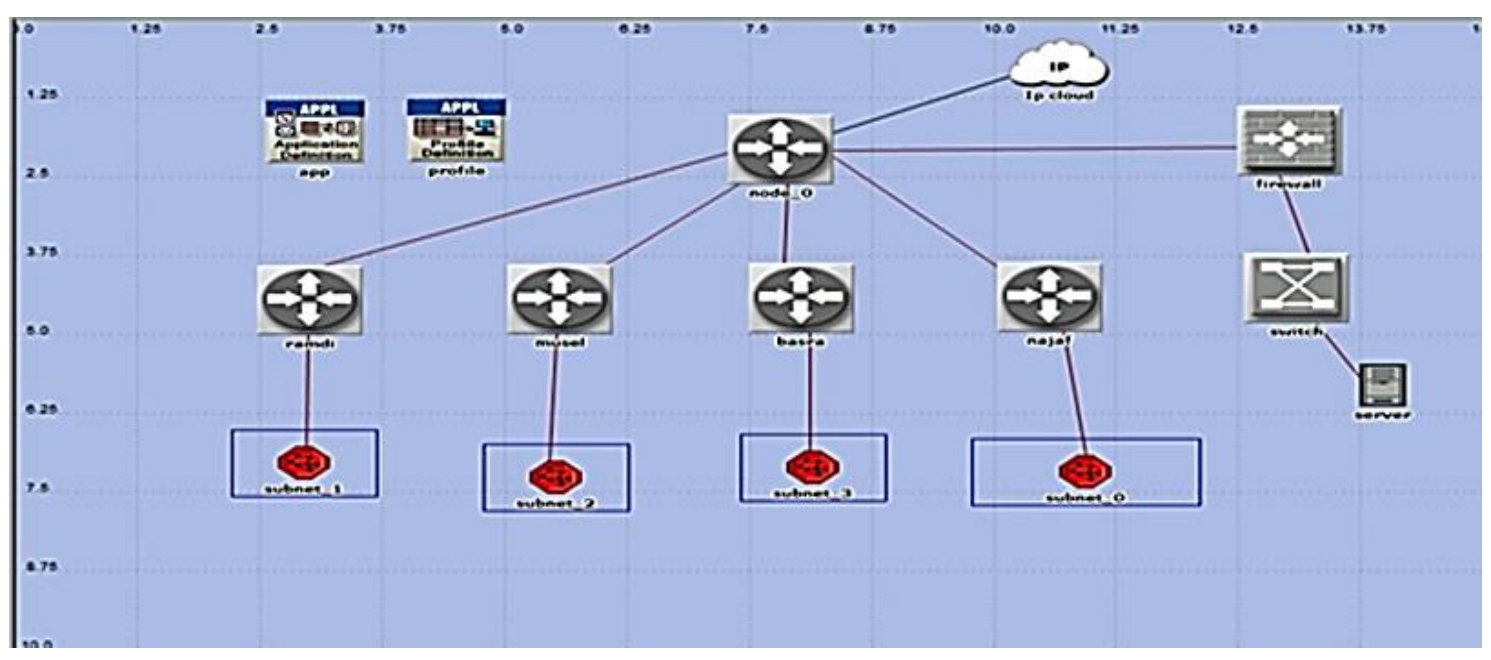

Figure 6. Simulated fiber server, with many subnets

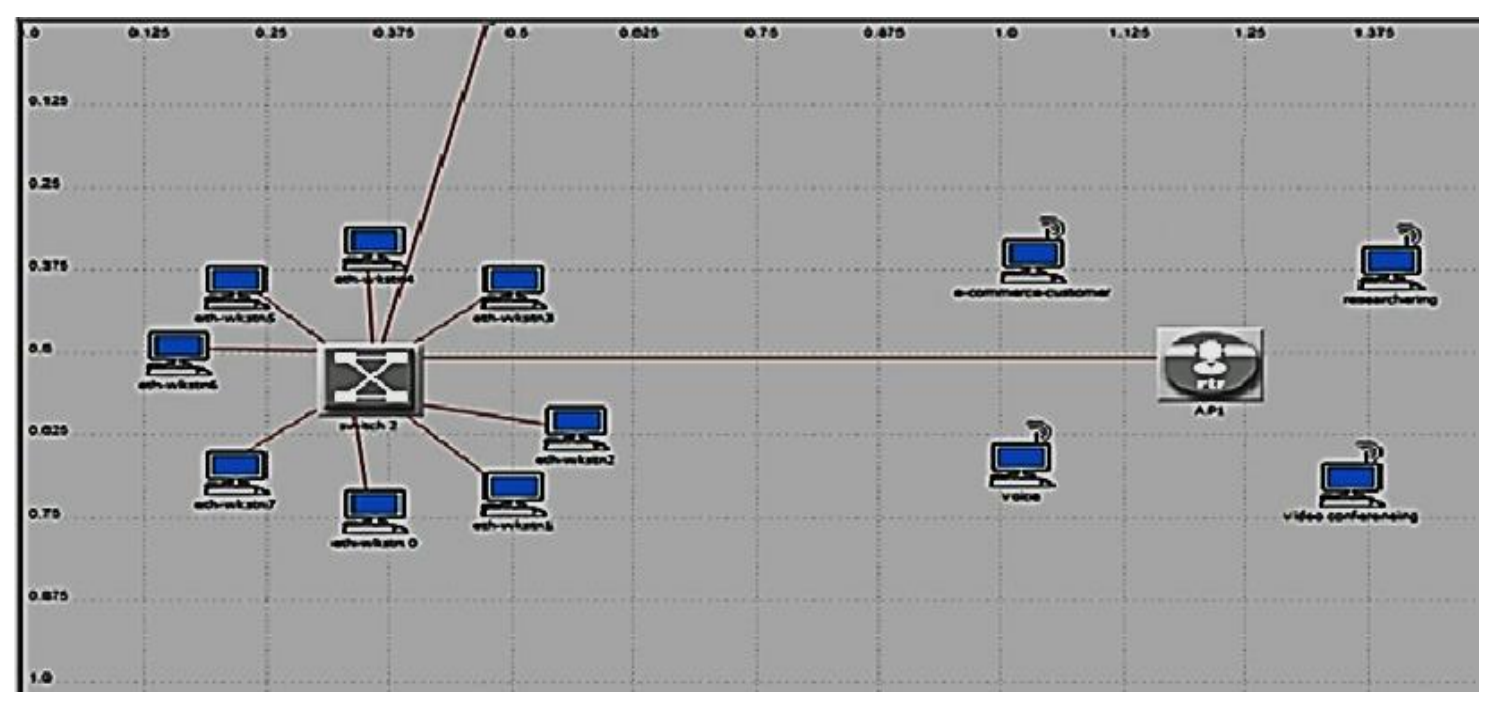

Figure 7. WiFi base fiber subnet 1

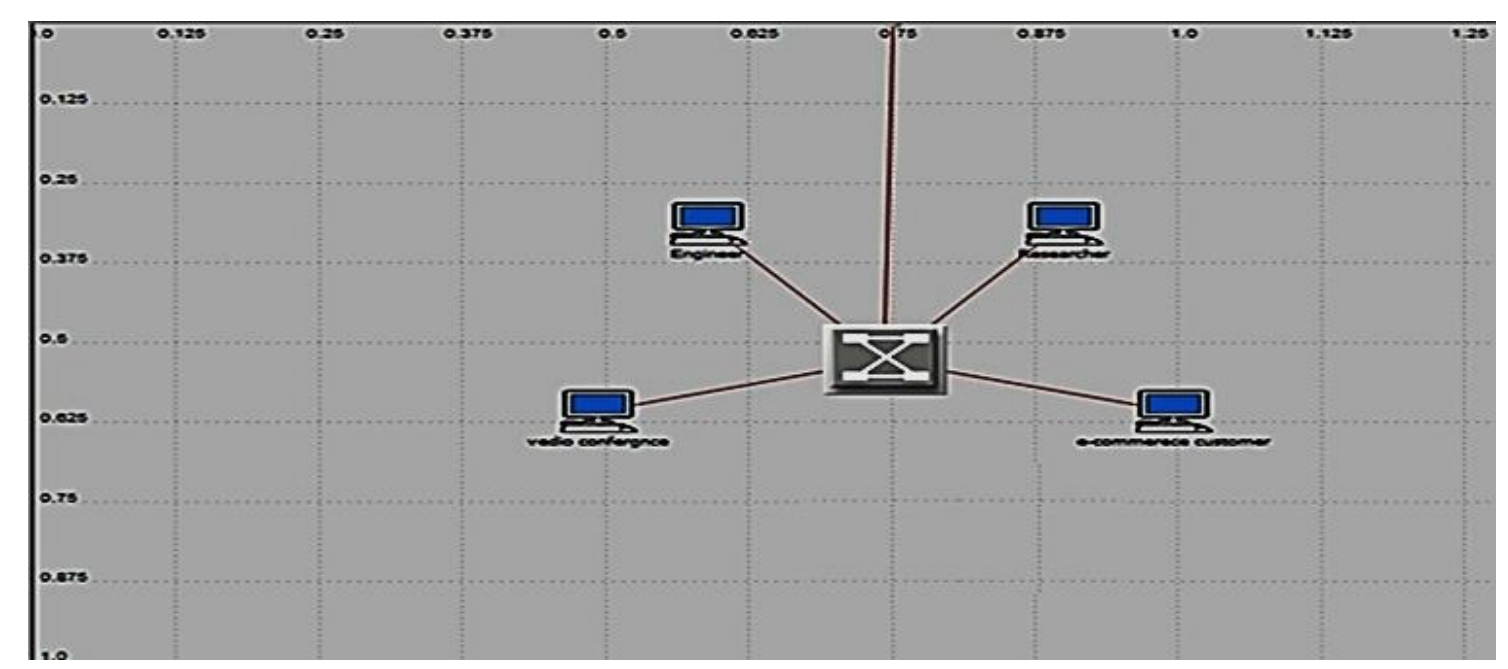

Figure 8. Wi-Fi base fiber subnet 2 


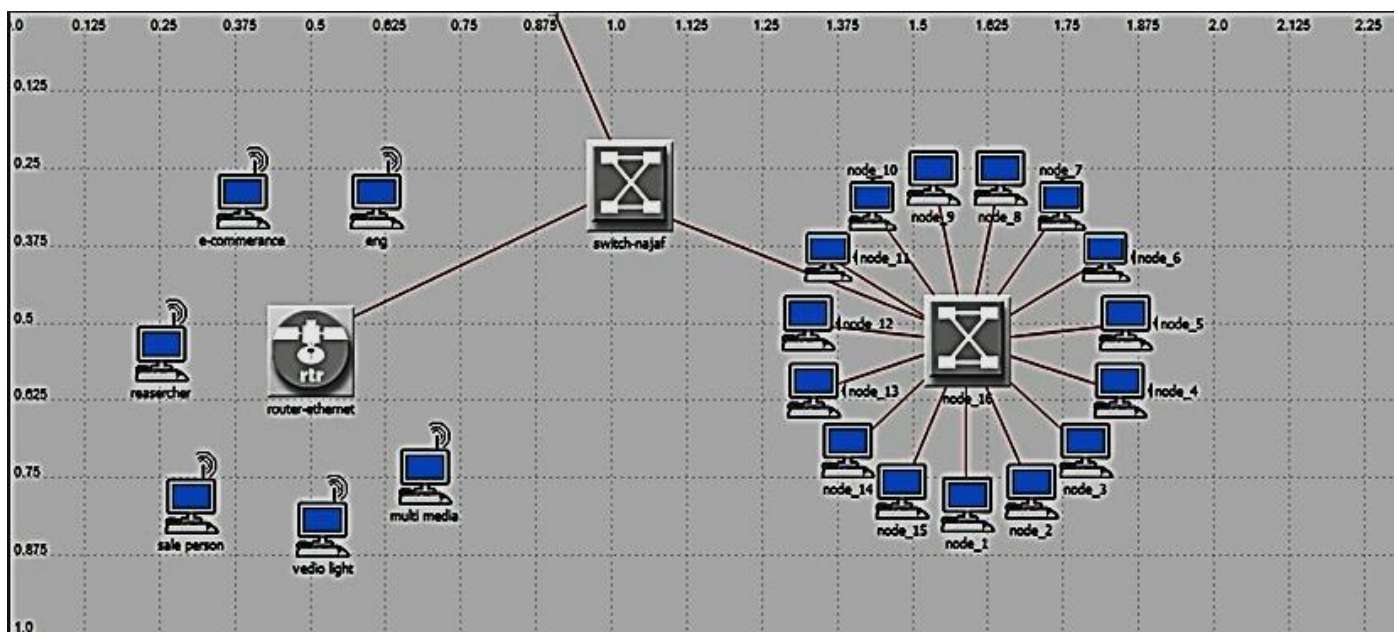

Figure 9. Wi-Fi base fiber subnet 3

\section{OPNET SIMULATION RESULTS}

OPNET has the capability of providing high-resolution modeling, simulated, and analyzing of WLAN networks like transmitter/receiver, overlap/interference and all protocols, which include routing, MAC, higher layer protocols and applications. In addition, it is also capable of integrating node mobility as well as establishing a relationship between wire line transport networks [11]. In the two scenarios, the use of two applications was employed in comparing the queuing delay and network load. This is explained using time delay measurements for both Wi-Fi base line and Wi-Fi base fiber. More so, this was used in measuring the voice-packet end to end delay for both Wi-Fi types of base line and base fiber. The simulation of all scenarios lasted for 350 seconds.

\subsection{Wi-Fi delay}

Upon the packet coming to the queue, the measurement of the average queuing delay begins till the moment the last bit of the packet is transmitted.

\subsubsection{End to end delay}

This delay premeditated as the average change between the transmission time intended for any data packet with a source entity and the time of the receiving packet with a receiver entity, after that averaged over the total receiver entities number. The simulation results for delay of the Wi-Fi based fiber optic connection is presented in Figure 10. Here, a network connection is established after $100 \mathrm{~s}$, and a state of stability is achieved by the communication system with a maximum delay of 0.042 second at $300 \mathrm{~s}$. Even though, the measurement for the end-to-end delay of the simulation of the Wi-Fi base line connection is shown in Figure 11. The simulation results show that no connections are available until $100 \mathrm{~s}$, where a network connection is established, and a state of stability is achieved by the communication system with a maximum delay of 0.048 second in the second 200. A comparison between the two measurements is shown in Figure 12, the wireless-delay based line connection is compared with the wireless-delay based fiber connection. The simulation results show that the baseline Wi-Fi delay at $200 \mathrm{~s}$ is $0.048 \mathrm{~s}$, while that of the Wi-Fi base fiber $0.035 \mathrm{~s}$. This implies that the delay for baseline Wi-Fi is greater than that of Wi-Fi base fiber.

\subsubsection{Wi-Fi voice-packet delay}

From the simulation result of the voice-packet end-to-end delay for Wi-Fi base fiber optic, it can be observed that no connection was found until at 110secs, where the network connection is established, and the network framework achieves a stable state with a maximum delay of 10 packets of 300 seconds, as shown (red line) in Figure 12. While, the end-to-end delay for Wi-Fi base line is presented. No link was found until $110 \mathrm{~s}$, where the network connection is established, and a steady state is reached by the communication system with a maximum delay of 1 packet at the 200 seconds. In Figure 13, the end-to-end delay for Wi-Fi base line connection voice-packet and the end-to-end delay for Wi-Fi base fiber connection are compared. Based on the simulation results, at 200 seconds the baseline Wi-Fi had 1 voice-packet delay, while that of the Wi-Fi base fiber was 4 voice-packet delay. It is therefore concluded that the voice-packet delay of the base fiber Wi-Fi is more than that of Wi-Fi base line. 


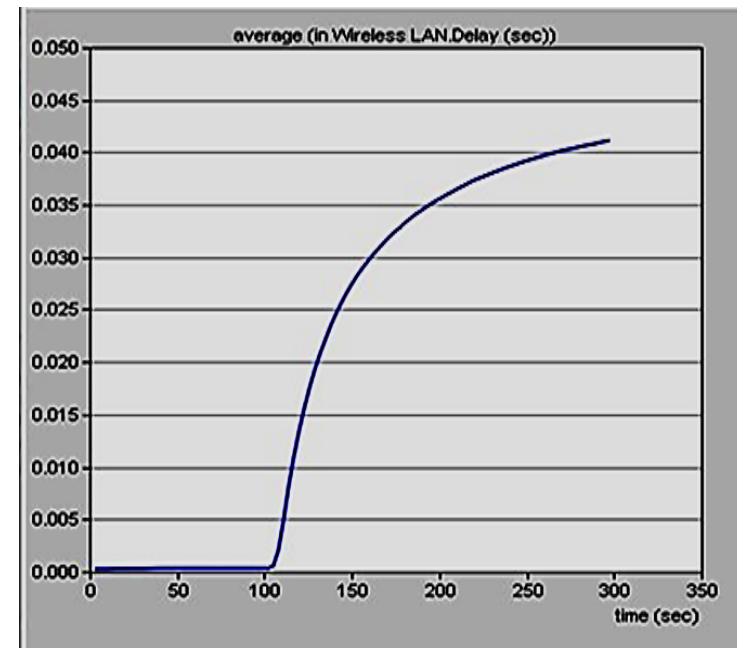

Figure 10. wireless-delay based fiber connection

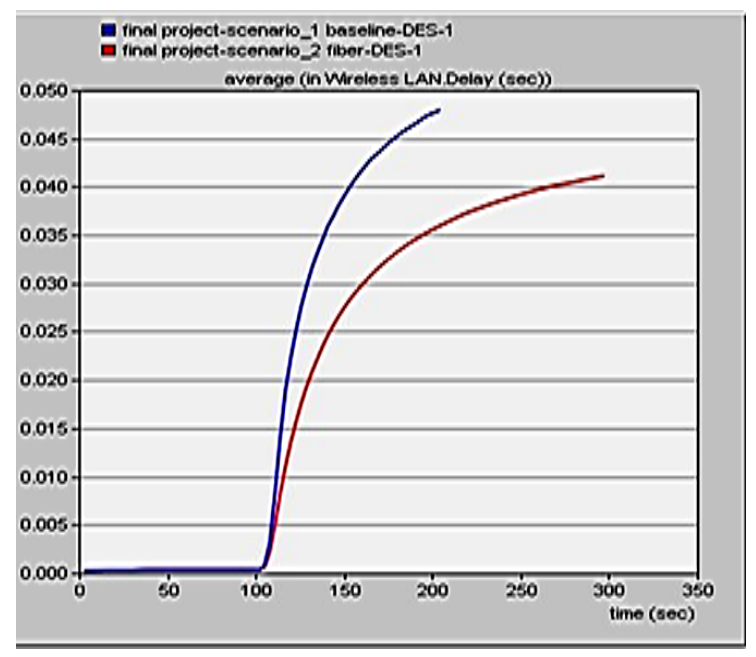

Figure 12. Delay compares between Wi-Fi base fiber and Wi-Fi base line

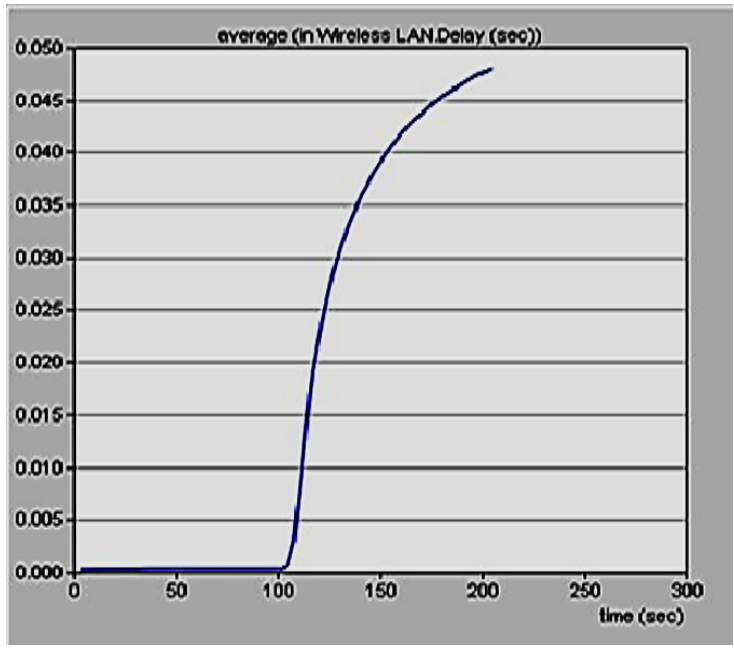

Figure 11. wireless-delay based line connection

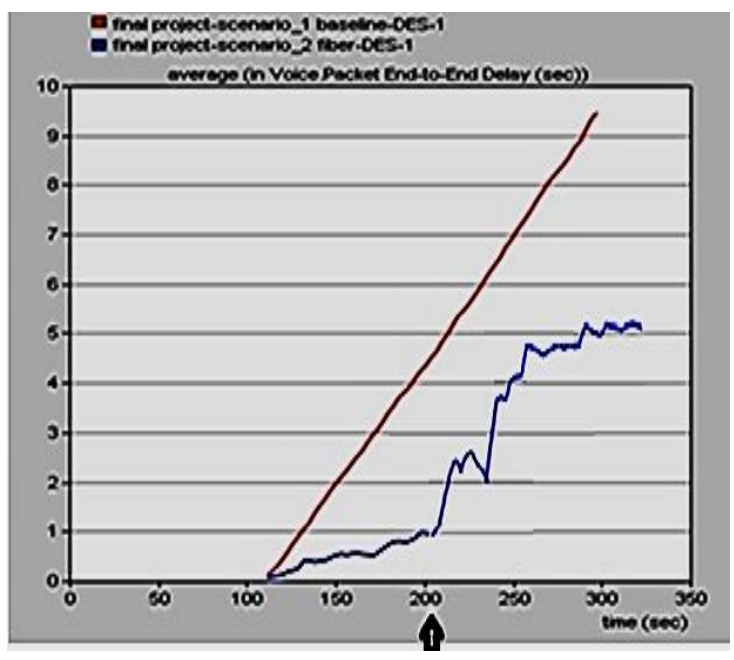

Figure 13. voice delay comparing between Wi-Fi base fiber and Wi-Fi base line

\section{CONCLUSION}

Identifying those bases and parameters that had been affected the Quality of Service (QoS) of the average End-to-End Delay and voice packet Delay through Wi-Fi networks and between Wi-Fi base fiber connection and base line connection are executed utilizing the OPNET simulation tool. The optimization of the networks for both scenarios to alleviate the QoS impairment are discussed. The results of a comparison of the both scenarios are presented in Figures 12 and 13. The results show the ratio of average End-to-End Delay and voice- packet Delay as a simulation run time functions used with this study, the delay of the base line Wi-Fi is more than that of Wi-Fi delay base fiber. The voice-packet delay of base fiber Wi-Fi is more than that of Wi-Fi base line.

\section{REFERENCES}

[1] Zainab T. Alisa, "Evaluating the Performance of Wireless Network using OPNET Modeler," International Journal of Computer Applications, vol. 62(13), Jan. 2013.

[2] Adnan H A, "Performance Evaluation of Wi-Fi Physical Layer Based QoS Systems on Fiber Using OPNET Modeler," International Journal of Soft Computing and Engineering (IJSCE), vol. 5(3), 2015.

[3] P. Trimintzios1 and G. Georgiou, "WiFi and WiMAX Secure Deployments," Journal of Computer Systems, Networks, and Communications, Article ID 423281, vol. 2010, 2010. 
[4] Adnan H. Ali, Ali N. A, and Maan H. H, "Performance Evaluation of IEEE802.11g WLANs Using OPNET Modeler," American Journal of Engineering Research (AJER), vol. 2(12), pp. 09-15. 2013

[5] L.M.S.C. of the IEEE Computer Society, "Wireless LAN Medium Access Control (MAC) and Physical Layer (PHY) specifications: Higher-Speed Physical layer Extension in the $2.4 \mathrm{GHz}$ Band," ANSI/IEEE Standard 802.111999TM, 1999.

[6] Kritika, N and Namarta, "Performance Evaluation of 802.11 WLAN Scenarios in OPNET Modeler," International Journal of Computer Applications, May 2011.

[7] Adnan H. Ali and Farhood, A.D, "Design and Performance Analysis of the WDM Schemes for Radio over Fiber System with Different Fiber Propagation Losses," Fibers, vol. 7, pp. 19, 2019.

[8] H. Zhu, M. Li, I. Chlamtac and B. Prabhakaran, "A survey of quality of service in IEEE 802.11 networks," IEEE Wireless Communications, 2004.

[9] Garima Malik and Ajit Singh, "Performance Evaluation of WiFi and WiMax Using Opnet," International Journal of Advanced Research in Computer Science and Software Engineering, vol. 3(6), Jun. 2013.

[10] Mohammed, H.A.; Ali and Adnan H, "Effect of some security mechanisms of the Qos VoIP application using OPNET," Int. J. Curr. Eng. Technol, vol. 3(5), pp. 1626-1630, 2013.

[11] L. Das Dhomeja, Shazia Abbasi, Asad Ali Shaikh1 and Y. A. Malkani, "Performance Analysis of Wlan Standards for Video Conferencing Applications," International Journal of Wireless \& Mobile Networks (IJWMN), vol. 3(6), Dec. 2011.

[12] Adnan H. Ali, "Simultaneous Measurements for Tunable Laser Source Linewidth with Homodyne Detection," Computer and Information Science, vol. 4(4), Jul. 2011.

[13] Eldad Perahia and Michelle X. Gong, "Gigabit Wireless LANs: an overview of IEEE 802.11ac and 802.11ad," Intel Corporation, Jan. 2011.

[14] Hussein, A, Adnan, H. Ali, and Hawraa, J, "The Affects of Different Queuing Algorithms within the Router on QoS VoIP application Using OPNET," International Journal of Computer Networks \& Communications (IJCNC), vol. 5(1), pp. 117-124, 2013.

[15] M. M. Kareem, M. Ismail, M. A. Altahrawi, N. Arsad, M. F. Mansor, and A. H. Ali, "Grid Based Clustering Technique in Wireless Sensor Network using Hierarchical Routing Protocol," in 2018 IEEE 4th International Symposium on Telecommunication Technologies (ISTT), pp. 1-5, 2018.

[16] Ali A. Abdulrazzaq and Adnan H. Ali, "Efficiency Performances of Two MPPT Algorithms for PV System with Different Solar Panels Irradiances," International Journal of Power Electronics and Drive System (IJPEDS), vol. 9(4), pp. 1755-1764, Dec. 2018.

[17] Samir A. Lafta, Aktham H. Ali, Marwah M. Kareem, Yasser A. Hussein, and Adnan H. Ali, "Performance simulation of broadband multimedia wireless networks simulation based on OPNET," IJEECS, vol. 17(2), pp. 1005-1013, Feb. 2020.

[18] Ali A. Abdulrazzaq and Adnan H. Ali, "Performance Investigation of Grid Connected Photovoltaic System Modelling Based on MATLAB Simulation," International Journal of Electrical and Computer Engineering (IJECE), vol. 8(6), 2018.

[19] Adnan H. Ali, Hayder J. Alhamdane, and Begared S. Hassen, "Design analysis and performance evaluation of the WDM integration with CO-OFDM system for radio over fiber system," Indonesian Journal of Electrical Engineering and Computer Science, vol. 15(2), pp. 870-878, Aug. 2019.

[20] M. A. Saad, Mustafa S. T., M. H. Ali, M. M. Hashim, M. Bin Ismail, and Adnan H. Ali, "Spectrum sensing and energy detection in cognitive networks," Indonesian Journal of Electrical Engineering and Computer Science, vol. 17(1), pp. 465-472, Jan. 2020.

[21] Ahmed J. Abid, Fawzi M. Al-Naima, and Adnan H. Ali, "Comprehensive Modeling of Photovoltaic Array based on Proteus Software," International Journal of Applied Engineering Research, vol. 13(6), May 2018.

[22] Adnan H. Ali and Ahmed R. Ajel, "OPNET Scenarios of WiFi and WIMAX Networks Performance Analysis," International Journal of Innovative Technology and Exploring Engineering (IJITEE), vol. 6(4), Sep. 2016.

[23] Adnan H. Ali, Haeeder M. Noman, and Hassan S. Hamad, "Analytical Execution of Dynamic Routing Protocols for Video Conferencing Applications Based on OPNET Modeler," The International Journal Of Engineering And Science (IJES), vol. 6(3), pp. 49-56, 2017.

[24] Ali, A.H and Abdul-Wahid, S.N, "Analysis of self-homodyne and delayed self-heterodyne detections for tunable laser source linewidth measurements," IOSR J. Eng, vol. 2(10), pp. 1-6, 2012.

[25] OPNET Technologies, "OPNET WORK 2007 proceedings," 2007. [Online] Available: http://www.opnet.com /opnetwork2007. 